\title{
A simple method for quantification of uncultured microorganisms in the environment based on in vitro transcription of $16 \mathrm{~S}$ rRNA
}

\section{Citation}

Polz, Martin F., and Colleen M. Cavanaugh. 1997. "A simple method for quantification of uncultured microorganisms in the environment based on in vitro transcription of $16 \mathrm{~S}$ rRNA." Applied and Environmental Microbiology 63 (3): 1028-1033.

\section{Published Version}

http://aem.asm.org/content/63/3/1028.full.pdf+html

\section{Permanent link}

http://nrs.harvard.edu/urn-3:HUL.InstRepos:14352856

\section{Terms of Use}

This article was downloaded from Harvard University's DASH repository, and is made available under the terms and conditions applicable to Other Posted Material, as set forth at http:// nrs.harvard.edu/urn-3:HUL.InstRepos:dash.current.terms-of-use\#LAA

\section{Share Your Story}

The Harvard community has made this article openly available.

Please share how this access benefits you. Submit a story.

\section{Accessibility}




\title{
A Simple Method for Quantification of Uncultured Microorganisms in the Environment Based on In Vitro Transcription of 16S rRNA
}

\author{
MARTIN F. POLZ AND COLLEEN M. CAVANAUGH* \\ Biological Laboratories, Harvard University, Cambridge, Massachusetts 02138
}

Received 1 August 1996/Accepted 6 January 1997

\begin{abstract}
A simple method for the quantification of uncultured microorganisms in the environment was developed. In vitro-transcribed $16 \mathrm{~S}$ rRNA is used as a template for midpoint dissociation temperature $\left(T_{d}\right)$ determinations of specific oligonucleotide probes and as a standard in quantitative probing. It replaces the need for total nucleic acids extracted from pure cultures of the organisms to be quantified. A sense RNA of a size almost identical to that of native 16S rRNA can be transcribed from ribosomal DNA clones recovered in studies of the phylogenetic diversity of microbial communities. This in vitro-transcribed rRNA yields dissociation curves typical of oligonucleotides. They parallel curves determined with total nucleic acids but yield slightly higher $T_{d}$ values. Neither unspecific sticking of the probe nor probe washing off the DNA template at low temperatures fully accounted for the discrepancy in probe release from the two templates. This suggests that the native rRNA itself has melting characteristics different from those of its in vitro-transcribed counterpart. However, this difference does not affect the performance of in vitro-transcribed rRNA compared with total nucleic acids as a standard in quantitative hybridizations. No difference was found between the estimates of the relative quantity of a single bacterial species in a mixed community obtained with the two standards, regardless of whether DNA was removed from the samples. This protocol will allow the large-scale quantification of the ecological importance of uncultured microorganisms in natural environments for the first time.
\end{abstract}

Some 25 years ago, quantitative analysis of community structure and dynamics raised our theoretical and practical understanding of animal and plant ecology to a new level (21). However, in microbial ecology, the study of communities lagged behind because rigorously quantitative methodologies were not available. This was a reflection of traditional techniques of identification and enrichment since they are highly selective and generally recognize only a minor fraction of the overall diversity of microorganisms in samples from natural habitats. Today, at least in theory, these limitations are being overcome by the adaptation of molecular techniques to questions of microbial community structure and dynamics (for a recent review, see reference 2 ). A set of methods, known as the rRNA phylogenetic framework $(22,23)$, has been compiled that lets us estimate both constituents of ecological diversity in an environment (21): richness (i.e., the number of different populations) and evenness (i.e., the degree of dominance of individual populations).

In this rRNA phylogenetic framework, the richness, or number of different populations, can be estimated by exploring the genetic diversity of the microorganisms in a given sample. This is done by extracting nucleic acids, amplifying the $16 \mathrm{~S}$ rRNA gene by PCR with universally conserved primers, cloning and sequencing the gene fragments, and comparing the gene sequences. The resulting catalogues of sequences have generally shown that the majority of the microorganisms in the explored habitats had previously been unknown and that only a minor fraction of the microbial diversity had actually been captured on culture plates (see, for example, references 8, 9, 17, and 34). However, this approach in itself cannot yield reliable quantitative information on the relative importance of individual

\footnotetext{
* Corresponding author. Mailing address: Biological Laboratories,
} Harvard University, 16 Divinity Ave., Cambridge, MA 02138. Phone: (617) 495-2177. Fax: (617) 496-5854. species due to the potential for preferential amplification of certain sequences during PCR of mixtures of templates (30) and due to bias associated with variations in 16S rRNA gene copy numbers across species (7). Therefore, quantification relies on analysis of the cells or the mixture of nucleic acids obtained from the original sample. Because the 16S rRNA is a mosaic of variable and conserved regions (35), oligonucleotide probes can be constructed that will specifically recognize individual sequences or sets of phylogenetically related sequences (32). These probes can serve as a means of reliable identification of single cells and quantification of populations or groups when used in situ $(1,6,10)$ or in quantitative slot blot (33) hybridizations, respectively.

Quantitative hybridization can provide an especially ecologically meaningful estimate of the evenness or dominance of individual populations because it provides a composite signal of their activity and abundance. The general protocol was first developed by Stahl et al. (33). Total, mixed nucleic acids extracted from different environmental sources are immobilized on membranes side by side with dilutions of pure nucleic acid standards from organisms whose contribution to the overall community is to be quantified. Subsequently, the membranes are hybridized with ${ }^{32} \mathrm{P}$-labeled oligonucleotide probes with different levels of specificity and the amount of bound probe is quantified and normalized by using the standard curves obtained with pure nucleic acids. A typical result is expressed as the percentage of a specific probe to a universal probe, such as one recognizing all members of the domain Bacteria or the domain Archaea.

One major limitation of current protocols of quantitative hybridization is that the organism to be quantified has to be available in pure culture (33). Nucleic acids of pure cultures are needed as standards in the actual quantification and for the determination of midpoint dissociation temperatures $\left(T_{d} \mathrm{~s}\right)$ for the probes, since at this temperature good hybridization spec- 
ificity can be achieved while maintaining a strong signal (29). However, uncultured species, which can make up the majority of the diversity encountered, have been found to be dominant in some environments in which quantification without available pure cultures was possible $(25,31)$. With this in mind, we have developed and tested a method that significantly expands the application of quantitative hybridization by generating nucleic acid standards for the quantification of uncultured microorganisms. rRNA transcribed from cloned templates is shown to afford a quantitative estimate of a species added at different concentrations to an artificially assembled community. This replaces the need for nucleic acid standards obtained from pure cultures of the organisms to be quantified.

\section{MATERIALS AND METHODS}

Bacterial strains. Vibrio fischeri ES1114 and Vibrio anguillarum 775 were generous gifts of Edward Ruby (University of Southern California, Los Angeles). Cells were grown at room temperature in SWT medium, containing (per liter) $5 \mathrm{~g}$ of Bacto Tryptone (Difco Laboratories), $3 \mathrm{~g}$ of yeast extract (Difco), $3 \mathrm{ml}$ of glycerol, $700 \mathrm{ml}$ of filtered seawater, and $300 \mathrm{ml}$ of distilled water (19).

Nucleic acid extraction. Total nucleic acids from both Vibrio strains were extracted and purified by the method of Jarrell et al. (11) with slight modifications (24) and without RNase A treatment. Nucleic acids of Bacillus subtilis RL202 were extracted by the method of Cutting and Vander Horn (5) and were a generous gift of Len Duncan (Harvard University, Cambridge, Mass.). Nucleic acids of Bifidobacterium breve ATCC 15698 and Bifidobacterium bifidum ATCC 11863 were a generous gift of Dennis Roy (Food Research and Development Centre, Saint-Hyacinthe, Quebec, Canada). They were extracted by the method of Klaenhammer (14) and precipitated with cetyltrimethylammonium bromide$\mathrm{NaCl}(4)$.

PCR amplification and cloning. The gene coding for the 16S rRNA (16S rDNA) of $V$. anguillarum was amplified for the generation of (i) a gene fragment for cloning and (ii) a template for in vitro transcription. For the first purpose, $V$. anguillarum DNA was amplified with the primer pair $8 \mathrm{f}$ and $1492 \mathrm{r}$ (16). Both are among the standard primers used for near-universal amplification of bacterial $16 \mathrm{~S}$ rRNA genes, and their use results in a product that encompasses all but 56 of the 1,542 bases of the 16S rDNA (Escherichia coli standard). For the second purpose, the 16S rDNA fragment was ligated into the pCR II vector (Invitrogen, San Diego, Calif.) and transformed into and maintained in E. coli INV $\alpha \mathrm{F}^{\prime}$ according to the manufacturer's instructions. Plasmids containing inserts were purified by using a QIAprep Spin Plasmid Kit (Qiagen Inc., Chatsworth, Calif.) The inserts were amplified by PCR with a combination of one of the two M13 primers [M13 $(-40)$ forward or M13 reverse] flanking the insert on the plasmid and one of the 16S rRNA primers ( $8 \mathrm{f}$ or $1492 \mathrm{r}$ ). PCR was in all cases performed in an Ericomp Twin Block System thermal cycler (Ericomp, San Diego, Calif.) in $100-\mu \mathrm{l}$ aliquots. Each tube contained $1 \times$ PCR buffer $(50 \mathrm{mM} \mathrm{KCl}, 10 \mathrm{mM}$ Tris-HCl, $1 \%$ Triton X-100; $\mathrm{pH} 9.0), 200 \mu \mathrm{M}$ each deoxynucleoside triphosphate, $2.0 \mathrm{mM} \mathrm{MgCl}_{2}, 100 \mathrm{pM}$ each primer, $2.5 \mathrm{U}$ of $\mathrm{Taq}$ polymerase (Promega, Madison, Wis.), and $10 \mathrm{ng}$ of template. An initial denaturation step of $3 \mathrm{~min}$ at $94^{\circ} \mathrm{C}$ was followed by 35 cycles which consisted of $1 \mathrm{~min}$ at $94^{\circ} \mathrm{C}, 1 \mathrm{~min}$ at $50^{\circ} \mathrm{C}$, and 2 min at $72^{\circ} \mathrm{C}$

In vitro transcription. $r$ RNA was transcribed from PCR-generated templates by using T7 polymerase and an RNA transcription kit (Stratagene, La Jolla, Calif.). Prior to transcription, the templates were purified by excision of the correctly sized band from $0.8 \%$ agarose gels, electroelution of the DNA in a Centrilutor (Amicon, Beverly, Mass.), proteinase $\mathrm{K}$ treatment $(1 \mathrm{mg} / \mathrm{ml})$, and phenol-chloroform extraction, followed by ethanol precipitation (4). After completion of transcription, the DNA template was removed by treatment with RNase-free DNase (Gibco BRL, Gaithersburg, Md.) and the rRNA was purified on a $6 \%$ acrylamide gel, electroeluted, and ethanol precipitated. The RNA concentration was determined by spectrophotometry.

Oligonucleotide probe choice, labeling, and determination of $\boldsymbol{T}_{d}$. Two oligonucleotide probes, Van219 (CCUAGGCAUAUCCUGACGCG; positions 219 to 238 in E. coli numbering) and Eub338 (32). Van219 allows differentiation of $V$. anguillarum from the other bacterial strains used in this study (26), whereas Eub338 is nearly universal for all members of the domain Bacteria.

Oligonucleotides were labeled with polynucleotide kinase (Gibco BRL) by using 2 pmol of $\left[\gamma^{-32} \mathrm{P}\right]$ ATP $(6,000 \mathrm{Ci} / \mathrm{mmol}$; Du Pont NEN, Boston, Mass.) for each picomole of probe. The approximate specific activities of the labeled probes were in all cases between $7 \times 10^{6}$ and $1 \times 10^{7} \mathrm{cpm} / \mathrm{pmol}$. Probes were purified on NenSorb 20 cartridges (Du Pont NEN) according to the manufacturer's instructions.

For determination of the $T_{d}$ values of the oligonucleotides, the general strategy of Raskin et al. (29) was employed with modifications that diminish the variability between replicates. Each nucleic acid type was blotted in duplicate with a Minifold I dot blotter (Schleicher \& Schuell, Keene, N.H.) on Zetaprobe nylon membranes (Bio-Rad, Hercules, Calif.) by formamide-formaldehyde denaturation (4). Per replicate dot, approximately 300,150 , or $100 \mathrm{ng}$ of total nucleic acids, 16S rDNA (PCR generated), or purified rRNA was used, respectively. Hybridizations were done with the respective probes at $30^{\circ} \mathrm{C}$ overnight in buffer containing $50 \mathrm{mM} \mathrm{Na}_{2} \mathrm{HPO}_{4}$ (pH 7.2), $655 \mathrm{mM} \mathrm{NaCl}, 7 \%$ sodium dodecyl sulfate and $2.5 \mu \mathrm{g} / \mathrm{ml}$ poly(A) (Sigma, St. Louis, Mo.). Subsequently, the membranes were washed twice for $15 \mathrm{~min}$ at the same temperature in wash buffer containing $50 \mathrm{mM} \mathrm{Na}_{2} \mathrm{HPO}_{4}(\mathrm{pH} 7.2)$ and $1 \%$ sodium dodecyl sulfate. Individual dots were then cut out and washed in $2 \mathrm{ml}$ of wash buffer contained in 7-ml scintillation vials which had been prewarmed in water baths ranging from 25 to $80^{\circ} \mathrm{C}$ at 2 to $5^{\circ} \mathrm{C}$ intervals. After $10 \mathrm{~min}$, the membranes were removed and radioactivity in the wash solution and on the membrane was determined by liquid scintillation counting. The $T_{d}$ values were calculated by dividing the counts remaining on the membranes by the total counts for each temperature point. Values were then plotted as the percentage of probe washed off versus temperature, and the temperature corresponding to $50 \%$ was taken as the $T_{d}$. To test for statistically significant effects of the template used, a two-way analysis of variance (ANOVA) was performed on arcsine-transformed ratios of the dissociation curves with the SYSTAT computer package.

Quantitative hybridizations. Nucleic acid blotting and hybridizations were done as described above with approximately a 10 -fold molar excess of probe over target and $2 \mathrm{ml}$ of hybridization buffer per dot. The two 15-min low-temperature washes were followed by one 10-min wash at the respective $T_{d} \mathrm{~s}$ of the probes used. Probe remaining bound to its target was analyzed by exposure of the membrane to a Fuji BAS-III imaging plate and quantified with a Fujix BAS2000 phosphorimager and BAS2000 Image File 2.1 analysis software. Nucleic acids to be quantified by phosphorimaging were spotted in five replicates and were (i) untreated, DNase-treated, and RNase-treated total nucleic acids of $V$. anguillarum; and (ii) a mixture of total nucleic acids of $V$. fischeri, Bacillus subtilis, Bifidobacterium breve, and Bifidobacterium bifidum simulating nucleic acids extracted from a natural community. To this artificial community, total nucleic acids of $V$. anguillarum were added in two different concentrations: 50 and $5 \%$ of the community. Because these values were determined by spectrophotometry and are influenced by the RNA/DNA ratios and genome sizes of the different organisms, they are reported as large and small additions. DNA was removed by DNase treatment from one subsample of each community with different $V$. anguillarum concentrations. These mixtures were hybridized with the universal probe Eub338 and the specific probe Van219 and then quantified by using the standard curves generated by dilution series of the following pure nucleic acids from $V$. anguillarum: (i) total nucleic acids extracted from pure cultures and (ii) in vitro-transcribed and purified rRNA. The least-squares method was used to determine the slopes and intercepts of the standard curves. The amount calculated for the Eub338 probe was treated as the total 16S rRNA present, and signals obtained for the Van219-specific probe are given as percentages of this total. To test for statistically significant differences among the treatments, paired $t$ tests and a three-way ANOVA were performed on the arcsine-transformed ratios with the SYSTAT computer package.

\section{RESULTS AND DISCUSSION}

Rationale and outline of protocol. While in search of alternatives to the use of total nucleic acids as standards in quantitative probing of not-yet-cultivated microorganisms, we deduced that $16 \mathrm{~S}$ rRNA alone can serve as a replacement. Most of the hybridization signal is likely to be contributed by rRNAs even if total nucleic acids are blotted and measured. First, in actively growing cells, most of the nucleic acids are rRNAs (20), and even in starving cells, the ratio between rRNA and actual ribosomal genes remains high (see, for example, references 13, 15, and 28). Second, RNA-DNA hybrids have a considerably higher melting temperature than DNA-DNA hybrids (12). Therefore, at the specific $T_{d}$ of the oligonucleotide probes, RNA should be measured at a much higher proportion than DNA even if the two are present in comparable amounts. Finally, if DNA contributed significantly to the observed signal, it could be easily removed from any sample by DNase treatment.

The starting point for the generation of rRNA standards for quantitative probing consists of $16 \mathrm{~S}$ rDNA clones obtained from studies determining the richness, or number of microbial populations, in a given habitat (Fig. 1). From these clones, RNA can be conveniently transcribed in vitro if a vector containing RNA polymerase promoters is chosen. We routinely use the pCR II vector, which facilitates cloning of Taq polymerase-amplified DNA because it contains a single thymidine overhang on both ends. However, such an overhang can be easily added to any blunt-ended vector (18), and a number of 


\author{
Pick rDNA clone \\ Determine orientation of insert \\ $\downarrow$ \\ PCR-amplify fragment containing \\ rDNA and RNA polymerase promoter
}

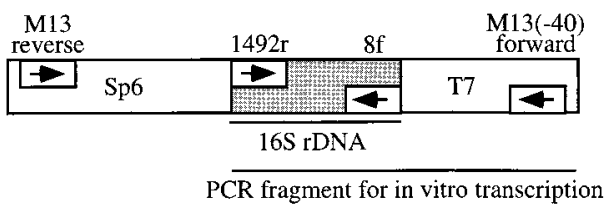

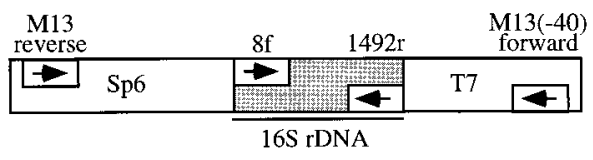

PCR fragment for in vitro transcription

\section{$\checkmark$}

Agarose gel purify PCR fragment, proteinase $\mathrm{K}$ treat, phenol:

chloroform extract and precipitate

Transcribe rRNA in vitro

DNase treat and acrylamide gel purify rRNA

FIG. 1. Flowchart of the protocol used for the generation of rRNA from clones recovered in studies of the phylogenetic diversity of microorganisms in the environment. A diagram of the plasmid configuration with the insert (shaded areas) drawn in the two possible orientations that will give a sense rRNA in in vitro transcription from the $\mathrm{T} 7$ and Sp6 promoters, respectively, is included (plasmids and inserts are not drawn to scale). T7 and Sp6, RNA polymerase promoters; M13 reverse and M13(-40) forward, universal M13 primer sites on the plasmid; $1492 \mathrm{r}$ and 8f, 16S rDNA primers used for the universal amplification of bacterial genes.

other PCR cloning vectors which contain RNA polymerase promoters have recently been made commercially available.

An rRNA of a length almost identical to that of the native molecule can be produced if PCR-generated templates are used in the in vitro transcription. The first step is the determination of insert orientation by PCR with one internal rDNA and one external plasmid primer (Fig. 1). Such a PCR product will also contain an RNA polymerase promoter since the insert is flanked on each side by one of two promoters (T7 or Sp6), each of which is followed by one M13 primer location (Fig. 1). For a sense strand of rRNA to be produced in the transcription process, an approximately 16-kb PCR product must be obtained with one of the following primer combinations: (i) M13(-40) forward and 1492r or (ii) M13 reverse and 1492r. In the in vitro transcription, the roughly 60 bases of the gene not amplified by the universal $16 \mathrm{~S}$ rRNA primers ( $8 \mathrm{f}$ and $1492 \mathrm{r}$ ) are replaced by a segment of the plasmid between the transcriptional start site and the beginning of the insert (Fig. 1). Clones were chosen that result in proper transcription with the M13(-40) forward and 1492r primer combination, since in this case the segment will amount to 67 bases as opposed to 80

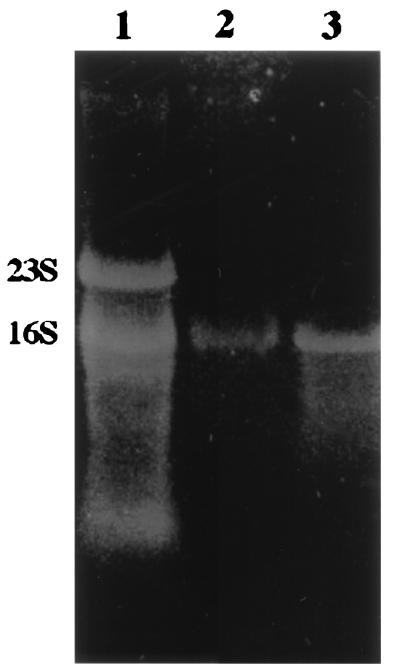

FIG. 2. Denaturing agarose gel electrophoresis of total nucleic acids of $V$. anguillarum (lane 1) and gel purified (lane 2) and unpurified (lane 3) in vitrotranscribed RNA.

bases for the other combination (Fig. 1). This rRNA was tested as a template for probe $T_{d}$ determination and as a standard in quantitative hybridizations.

Size and specificity of transcribed product. With the M13 $(-40)$ forward and 1492r primer combination, a product with almost exactly the same length as the native 16S rRNA was obtained by transcription from a PCR product (Fig. 2) as outlined above. In vitro-transcribed and gel-purified sense and antisense RNAs from $V$. anguillarum clones were used to test the hybridization properties of the specific probe Van219 and the universal probe Eub338 in dot blot assays (Fig. 3). These tests showed that these probes have a high degree of specificity for the sense strand and indicate that the PCR-generated DNA template is efficiently removed by DNase treatment after transcription. Both the size and the purity of the rRNA should make exact quantification by spectrophotometry possible. This allows the measurement of absolute amounts of rRNA present in environmental samples by comparison with the standard curves obtained with in vitro-transcribed rRNA.

Comparison of $T_{d}$ determinations performed with total nucleic acids or rRNA as the template. Use of in vitro-transcribed rRNA and total nucleic acids as templates in $T_{d}$ determinations of the oligonucleotide probes Eub338 and Van219 gave comparable results (Fig. 4). Although at lower temperatures the probes are more readily washed off the total nucleic acids than they are washed off the rRNA alone, resulting in an overall significant difference $(P<0.001)$, the two curves con-

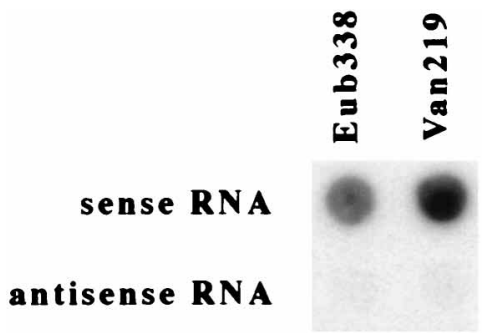

FIG. 3. Dot blot assay of in vitro-transcribed sense (row 1) and antisense (row 2) strand rRNA hybridized with probe Eub338 (column 1) and probe Van219 (column 2). 

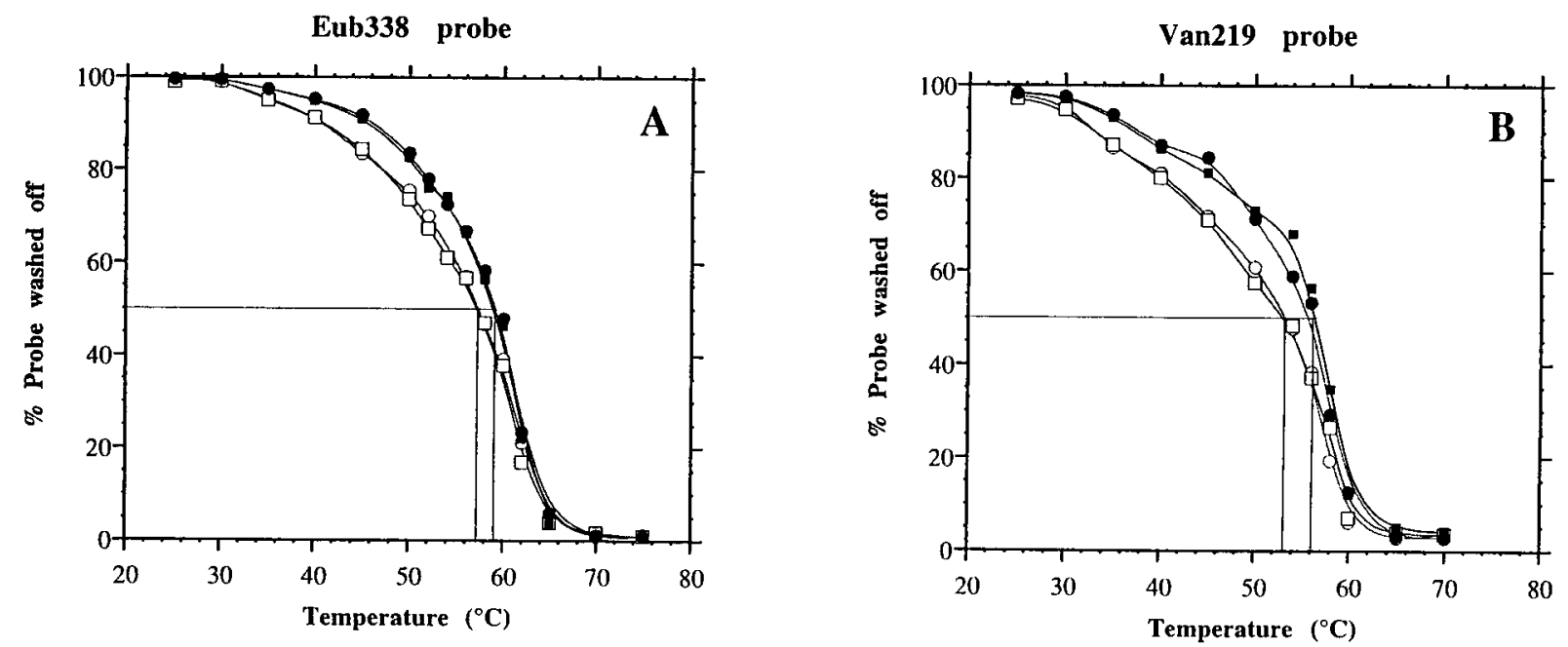

FIG. 4. Determination of the oligonucleotide $T_{d}$ values of the universal probe Eub338 (A) and the specific probe Van219 (B), using total nucleic acids extracted from pure cultures of $V$. anguillarum $(O$, replicate $1 ; \square$, replicate 2$)$ and in vitro-transcribed and purified rRNA of the same species $(\bullet$, replicate 1 ; $\mathbf{\square}$, replicate 2$)$ as template.

verge with increasing wash temperatures. At the $50 \%$ mark, approximate differences in $T_{d}$ of only 2 and $3^{\circ} \mathrm{C}$ are observed for the Eub338 and the Van219 probes, respectively. Three possible phenomena could explain this discrepancy in the $T_{d}$ curves: (i) the oligonucleotide probe sticks nonspecifically to the DNA and other RNAs in the total nucleic acids and is gradually removed as the temperature increases; (ii) the probe binds specifically to its target, but a larger proportion is washed off the DNA template at lower temperatures because DNADNA hybrids have a lower degree of thermal stability than RNA-DNA hybrids; or (iii) an intrinsic difference between native rRNA and in vitro-transcribed rRNA influences probe binding. The first two possibilities were evaluated in a series of experiments using the Eub338 probe and are discussed in the context of general experimental design. Furthermore, tests were performed to determine whether the observed differences in $T_{d}$ would affect quantitative probing results.

Nonspecific sticking of probe was found to be only a relatively minor factor in causing the differences in the shapes of the $T_{d}$ curves determined on total nucleic acids or rRNA alone. To determine whether probe stuck to DNA nonspecifically in the total nucleic acid standard, five replicates of each DNasetreated, RNase-treated, and untreated nucleic acid were hybridized with the Eub338 probe and the amount of probe bound after the two low-temperature washes and, subsequently, after the high-temperature $T_{d}$ wash was quantified. When the pairwise ratios of the mean signals of the three treatments were calculated, no significant difference was found between the pre- and post- $T_{d}$ wash samples. For example, the difference between the ratios of the DNase-treated and untreated nucleic acids for the low- and high-temperature washes was only $0.2 \%$, indicating that surplus probe is efficiently washed away in the two low-temperature washes following the hybridization. Likewise, a Northern hybridization with total RNA gave no evidence of nonspecific sticking to RNAs other than $16 \mathrm{~S}$ rRNA, since no difference in the pre- and post- $T_{d}$ wash patterns was observed (data not shown).

Determination of the $T_{d}$ of the Eub338 probe on PCRgenerated rDNA leads to a considerably flatter curve than that obtained when total nucleic acids or rRNA alone is used as the template (Fig. 5). In addition, the $T_{d}$ lies more than $10^{\circ} \mathrm{C}$ lower, and almost all of the probe is washed off at temperatures below $60^{\circ} \mathrm{C}$. This suggests that very little probe remains bound to the DNA template at the $T_{d} \mathrm{~s}$ of the Eub338 probe determined on total nucleic acid and rRNA templates (Fig. 5). It was not determined whether the denaturation conditions used for the nucleic acids before blotting were a factor in the extremely low $T_{d}$ of the probe-DNA hybrid. In quantitative hybridizations, blotting of the nucleic acids has to be optimized for RNA since conditions used for DNA may degrade RNA. Thus, given these conditions and the observed low $T_{d}$, DNA may generally account for only a small proportion of the total signal obtained even when the RNA/DNA ratio is low.

While both nonspecific sticking and release of probe due to lower DNA-DNA duplex stability appear to be factors in the observed differences in the dissociation curves, they are unlikely to fully account for them. The rDNA hybridization template is generally several hundredfold to several thousandfold less abundant than the rRNA target in actively growing cells (13) and will consequently contribute little to the overall

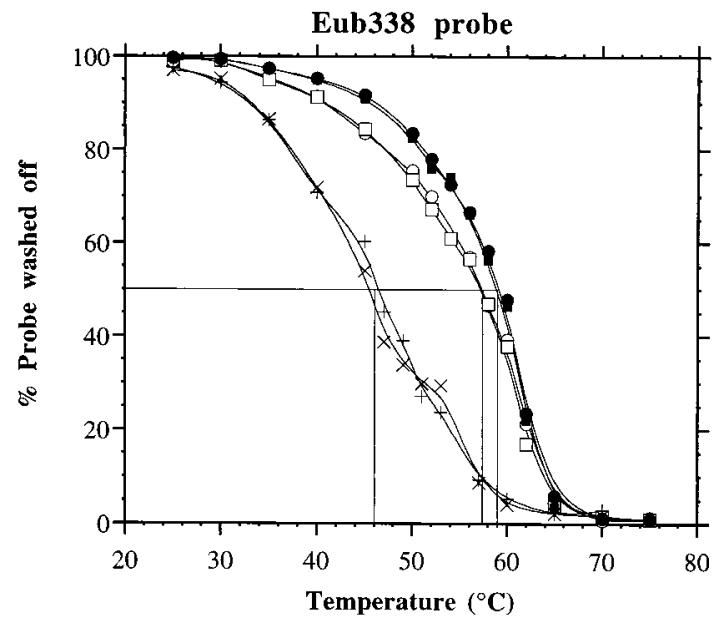

FIG. 5. Determination of the oligonucleotide $T_{d}$ of probe Eub338, using PCR-generated rDNA of $V$. anguillarum as template $(\times$, replicate $1 ;+$, replicate 2). The $T_{d}$ curves determined on total nucleic acids and rRNA alone (from Fig. 4A) are drawn for comparison. 
TABLE 1. Comparison of quantitative estimates of the abundance of $V$. anguillarum nucleic acids in a community, with total nucleic acids from a pure culture and in vitro-transcribed rRNA as standards ${ }^{a}$

\begin{tabular}{lccllc}
\hline \multirow{2}{*}{ Standard } & \multicolumn{2}{c}{ Relative quantity of $V$. anguillarum nucleic acids $(\%)^{b}$} \\
\cline { 2 - 3 } \cline { 5 - 6 } & \multicolumn{2}{c}{ Large amount } & & \multicolumn{2}{c}{ Small amount } \\
\cline { 2 - 3 } \cline { 5 - 6 } & Untreated & DNase treated & & Untreated & DNase treated \\
\hline Total nucleic acid & $18.6 \pm 5.4$ & $17.9 \pm 3.5$ & & $1.1 \pm 0.7$ & $1.0 \pm 0.7$ \\
rRNA & $19.3 \pm 6.1$ & $20.0 \pm 5.3$ & & $1.7 \pm 0.8$ & $1.6 \pm 0.6$ \\
\hline
\end{tabular}

${ }^{a}$ Nucleic acids of $V$. anguillarum were added in large and small amounts to an artificial community consisting of nucleic acids of four other species. DNA was removed by DNase treatment from one subsample of each treatment, and all four samples were blotted in five replicates. Dilutions of total nucleic acids of $V$. anguillarum and in vitro-transcribed rRNA were included as standards. The membranes were then hybridized with the ${ }^{32} \mathrm{P}$-labeled oligonucleotide probes Eub338 and Van219 and washed at the respective $T_{d} \mathrm{~s}$ of the probes.

${ }^{b}$ Ratios were calculated from hybridization signals of the Van219 and the Eub338 probes for each treatment and were arcsine transformed before determination of averages and standard deviations $(n=5)$ and performance of paired $t$ tests and a three-way ANOVA. Each value is reported as the sine of the average \pm the standard deviation (times 100).

amount of bound probe. Thus, there appears to be an intrinsic difference in hybridization behavior between the native and in vitro-transcribed rRNAs. However, this difference is very small at the $T_{d}$ and gradually disappears with increasing temperature. Whether modified bases in the native rRNA or other interactions cause greater dissociation at lower temperatures remains undetermined at this point.

Comparison of quantitative probing with total nucleic acids or rRNA as a standard. Essentially identical results were obtained when the relative importance of a single bacterial species in an overall community was determined with total nucleic acids or in vitro-transcribed rRNA as a standard. Table 1 summarizes the results of experiments in which total nucleic acids of $V$. anguillarum were added to mimic a major quantity and a minor quantity in the artificial community consisting of $V$. fischeri, Bacillus subtilis, Bifidobacterium breve, and Bifidobacterium bifidum. Quantification of the hybridization signals of the Eub338 and Van219 probes and calculation of their ratios revealed no significant difference $(P<0.001$ for all cases $)$ between the two standards regardless of whether total nucleic acids or DNase-treated nucleic acids from the community were blotted (Table 1). However, the ratios estimated by using the rRNA standard curves were in all cases slightly higher. Whether this represents a real difference cannot be determined since all between-treatment estimates were within $3 \%$ of each other and, thus, well within signal variability among replicate dots on the hybridization membrane (Table 1) (see also reference 3 ). This close agreement of the estimates indicates that the slight difference in $T_{d}$ values does not detectably influence estimates and that reliable quantification of single bacterial species in an overall community can be achieved by using in vitro-transcribed rRNA.

The similarity of the hybridization results for untreated and DNase-treated nucleic acids in the quantification of $V$. anguillarum in the total community (Table 1) gives further support to the probe dissociation studies (Fig. 5). These results suggest that most of the Eub338 probe is washed off the DNA at the $T_{d}$ determined on either total nucleic acids or rRNA alone (Fig. 5). Probe dissociation followed similar kinetics in a study of the Van219 probe done on RNase-treated nucleic acids (data not shown). Thus, in quantitative hybridizations of total community nucleic acids, DNA should contribute relatively little to the overall signal even in samples from some environments that have comparatively low rRNA/rDNA ratios.

Summary. We have determined that in vitro-transcribed rRNA may substitute for total nucleic acids as (i) a standard in quantitative probing of microbial community nucleic acids and (ii) a template for midpoint dissociation studies of oligonucleotide probes. The method is easy to use because it applies rDNA obtained from clones generated during assessment of the number of different types of microorganisms in a habitat. This application broadens the scope of quantitative analysis of microbial communities because it enables us to determine the relative importance of uncultured microorganisms in nature, a process which was previously not possible. For example, we have applied the method outlined here to the analysis of epibiotic microorganisms in the marine environment (27). This has enabled us for the first time to explore both aspects (richness and evenness) of the diversity of a microbial community from which no representative has yet been cultivated.

\section{ACKNOWLEDGMENTS}

This work was supported by grant N00014-91-J-1489 from the Office of Naval Research and by grant OCE-9314457 from the National Science Foundation.

We thank Edward Ruby, Len Duncan, and Dennis Roy for generously providing bacterial strains and nucleic acids used in this study, James McCloskey (University of Utah) for providing helpful comments on modified nucleosides in rRNA, and Bill Hoffmann (Harvard University) for assistance with statistical analyses.

\section{REFERENCES}

1. Amann, R. I., L. Krumholz, and D. A. Stahl. 1990. Fluorescent-oligonucleotide probing of whole cells for determinative, phylogenetic, and environmental studies in microbiology. J. Bacteriol. 172:762-770.

2. Amann, R. I., W. Ludwig, and K.-H. Schleifer. 1995. Phylogenetic identification and in situ detection of individual microbial cells without cultivation Microbiol. Rev. 59:143-169.

3. Anchordoguy, T. J., D. L. Crawford, I. Hardewig, and S. C. Hand. 1996 Heterogeneity of DNA binding to membranes used in quantitative dot blots. BioTechniques 20:754-756.

4. Ausubel, F. M., R. Brent, R. E. Kingston, R. E. Moore, J. G. Seidman, J. A Smith, and K. Struhl. 1990. Current protocols in molecular biology. Wiley Interscience, New York, N.Y.

5. Cutting, S. M., and P. B. Vander Horn. 1990. Genetic analysis, p. 27-74. In C. R. Harwood and S. M. Cutting (ed.), Molecular biological methods for Bacillus. John Wiley \& Sons, Inc., New York, N.Y.

6. DeLong, E., G. Wickham, and N. Pace. 1989. Phylogenetic stains: ribosomal RNA-based probes for the identification of single cells. Science 243:13601363.

7. Farrelly, V., F. A. Rainey, and E. Stackebrandt. 1995. Effect of genome size and $r r n$ gene copy number on PCR amplification of 16S rRNA genes from a mixture of bacterial species. Appl. Environ. Microbiol. 61:2798-2801.

8. Fuhrman, J. A., S. H. Lee, Y. Masuchi, A. A. Davis, and R. M. Wilcox. 1994. Characterization of marine prokaryotic communities via DNA and RNA. Microb. Ecol. 28:133-145.

9. Giovannoni, S. J., T. B. Britschgi, C. L. Moyer, and K. G. Field. 1990. Genetic diversity in Sargasso sea bacterioplancton. Nature 345:60-63.

10. Giovannoni, S. J., E. F. DeLong, G. J. Olsen, and N. R. Pace. 1988. Phylogenetic group-specific oligodeoxynucleotide probes for identification of single microbial cells. J. Bacteriol. 170:720-726.

11. Jarrell, K. F., D. Faguy, A. M. Herbert, and M. L. Kalmkoff. 1991. A general method of isolating high molecular weight DNA from methanogenic archaea (archaebacteria). Can. J. Microbiol. 38:65-68.

12. Keller, G. H., and M. M. Manak. 1989. DNA probes. Stockton Press, New York, N.Y.

13. Kerkhof, L., and B. B. Ward. 1993. Comparison of nucleic acid hybridization and fluorometry for measurement of the relationship between RNA/DNA ratio and growth rate in a marine bacterium. Appl. Environ. Microbiol. 59:1303-1309.

14. Klaenhammer, T. R. 1984. A general method for plasmid isolation in lactobacilli. Curr. Microbiol. 10:23-28.

15. Kramer, J. G., and F. L. Singleton. 1992. Variation in rRNA content of marine Vibrio spp. during starvation-survival and recovery. Appl. Environ. Microbiol. 58:201-207.

16. Lane, D. J. 1991. 16S/23S rRNA sequencing, p. 115-174. In E. Stackebrandt and M. Goodfellow (ed.), Nucleic acid techniques in bacterial systematics. 
John Wiley \& Sons, Chichester, United Kingdom.

17. Liesack, W., and E. Stackebrandt. 1992. Occurrence of novel groups of the domain Bacteria as revealed by analysis of genetic material isolated from an Australian terrestrial environment. J. Bacteriol. 174:5072-5078.

18. Marchuk, M., M. Drumm, A. Saulino, and F. S. Collins. 1991. Construction of T-vectors, a rapid and general system for direct cloning of unmodified PCR products. Nucleic Acids Res. 19:1154.

19. Nealson, K. H. 1978. Isolation, identification and manipulation of luminous bacteria. Methods Enzymol. 57:153-166.

20. Neidhardt, F. C., J. L. Ingraham, and M. Schaechter. 1990. Physiology of the bacterial cell: a molecular biological approach. Sinauer Associates, Sunderland, Mass.

21. Odum, E. P. 1971. Fundamentals of ecology. W. B. Saunders, Philadelphia, $\mathrm{Pa}$

22. Olsen, G. J., D. L. Lane, S. J. Giovannoni, and N. R. Pace. 1986. Microbial ecology and evolution: a ribosomal RNA approach. Annu. Rev. Microbiol. 40:337-365.

23. Pace, N. R., D. A. Stahl, D. L. Lane, and G. J. Olsen. 1986. The analysis of natural microbial populations by rRNA sequences. Adv. Microbiol. Ecol. 9:1-55.

24. Polz, M. F., E. V. Odintsova, and C. M. Cavanaugh. 1996. Phylogenetic relationships of the filamentous sulfur bacterium Thiothrix ramosa based on 16S rRNA sequence analysis. Int. J. Syst. Bacteriol. 46:94-97.

25. Polz, M. F., and C. M. Cavanaugh. 1995. Dominance of one bacterial species at a Mid-Atlantic Ridge hydrothermal vent site. Proc. Natl. Acad. Sci. USA 92:7232-7236.

26. Polz, M. F., and C. M. Cavanaugh. 1996. Unpublished data.

27. Polz, M. F., C. T. Harbison, and C. M. Cavanaugh. 1996. Symbiosis and microbial community structure, abstr. N-176, p. 352. In Abstracts of the 96th General Meeting of the American Society for Microbiology 1996. American Society for Microbiology, Washington, D.C.

28. Poulsen, L. K., G. Ballard, and D. A. Stahl. 1993. Use of rRNA fluorescence in situ hybridization for measuring the activity of single cells in young and established biofilms. Appl. Environ. Microbiol. 59:1354-1360.

29. Raskin, L., J. M. Stromley, B. E. Rittmann, and D. A. Stahl. 1994. Groupspecific 16S rRNA hybridization probes to describe natural communities of methanogens. Appl. Environ. Microbiol. 60:1232-1240.

30. Reysenbach, A.-L., L. J. Giver, G. S. Wickham, and N. R. Pace. 1992 Differential amplification of rRNA genes by polymerase chain reaction. Appl. Environ. Microbiol. 58:3417-3418.

31. Spring, S., R. Amann, W. Ludwig, K.-H. Schleifer, H. van Gemerden, and N. Petersen. 1993. Dominating role of an unusual magnetotactic bacterium in the microaerobic zone of a freshwater sediment. Appl. Environ. Microbiol. 59:2397-2403.

32. Stahl, D. A., and R. Amann. 1991. Development and application of nucleic acid probes, p. 205-248. In E. Stackebrandt and M. Goodfellow (ed.), Nucleic acid techniques in bacterial systematics. John Wiley \& Sons, Chichester, United Kingdom.

33. Stahl, D. A., B. Flesher, H. R. Mansfield, and L. Montgomery. 1988. Use of phylogenetically based hybridization probes for studies of ruminal microbial ecology. Appl. Environ. Microbiol. 54:1079-1084.

34. Ward, D. M., R. Weller, and M. M. Bateson. 1990. 16S rRNA sequences reveal numerous uncultured microorganisms in a natural community. Nature 345:63-65.

35. Woese, C. R. 1987. Bacterial evolution. Microbiol. Rev. 51:221-271. 